\title{
Engineering 3D Graphene-Based Materials: State of the Art and Perspectives
}

\author{
Luca Bellucci@ and Valentina Tozzini *(1) \\ Istituto Nanoscienze-CNR and NEST-Scuola Normale Superiore, Piazza San Silvestro 12, 56127 Pisa, Italy; \\ luca.bellucci@nano.cnr.it \\ * Correspondence: valentina.tozzini@nano.cnr.it; Tel.: +39-050-509-433
}

Received: 24 December 2019; Accepted: 10 January 2020; Published: 14 January 2020

\begin{abstract}
Graphene is the prototype of two-dimensional (2D) materials, whose main feature is the extremely large surface-to-mass ratio. This property is interesting for a series of applications that involve interactions between particles and surfaces, such as, for instance, gas, fluid or charge storage, catalysis, and filtering. However, for most of these, a volumetric extension is needed, while preserving the large exposed surface. This proved to be rather a hard task, especially when specific structural features are also required (e.g., porosity or density given). Here we review the recent experimental realizations and theoretical/simulation studies of 3D materials based on graphene. Two main synthesis routes area available, both of which currently use (reduced) graphene oxide flakes as precursors. The first involves mixing and interlacing the flakes through various treatments (suspension, dehydration, reduction, activation, and others), leading to disordered nanoporous materials whose structure can be characterized a posteriori, but is difficult to control. With the aim of achieving a better control, a second path involves the functionalization of the flakes with pillars molecules, bringing a new class of materials with structure partially controlled by the size, shape, and chemical-physical properties of the pillars. We finally outline the first steps on a possible third road, which involves the construction of pillared multi-layers using epitaxial regularly nano-patterned graphene as precursor. While presenting a number of further difficulties, in principle this strategy would allow a complete control on the structural characteristics of the final 3D architecture.
\end{abstract}

Keywords: graphene-based materials; nanoporous graphene; epitaxial graphene; molecular modeling

\section{Introduction}

Since the experimental confirmation of its existence [1], graphene has raised great expectations because of its exceptional properties, stemming from a fortunate combination of the electronic structure of carbon, the symmetry of its lattice, and its two-dimensional (2D) nature [2]. Besides the large charge carriers' mobility and the wide-band optical response, graphene displays extremely large resistance to tensile strain associated to a very low bending rigidity [3], leading among other things to the emergence of low energy transverse phonons [4] and ripples [5]. These properties associated to the low weight have triggered the proposal of a plethora of possible applications [6-10].

With little exceptions, however, these require some sort of manipulation of the sheet: in general nano-electronics requires doping to increase the density of states at the Fermi energy or to open a gap, which can be achieved by chemical substitutions [11], introduction of adatoms [12] or defects [13,14] or structure modulation [15,16]; for photovoltaics [9] different functionalization are required, depending on the specific use proposed (anode, cathode or photoactive layer [17]). Catalysis or environmental applications, such as water filtering, generally require sheet alteration, such as perforations of tailored size [18]. Recently, a brand new branch of investigation has stemmed from graphene in-plane large mechanical strength and elasticity [3], coupled to out of plane flexibility [5]: controlled local strain would 
create pseudo-magnetic fields [19], besides band-gap opening and other specific electronic structure modifications [20,21] with interesting applications in nano-electronics and photonics; both in-plane (strain [22]) and out-of-plane (rippling [23]) mechanical alterations were shown to locally change chemical reactivity opening the way to controlled chemical nano-patterning [24,25]. Interestingly, all of the suggested modifications correspond to controlled disruption of the perfect symmetry of the crystal in a different way, which leads to viewing grapheme-rather than a single material-as a sort of morphable platform to build a class of slightly different materials suitable to specific purposes [26,27].

In addition to the modification of the layer, a wide range of uses needs its volumetric extension, with the requirement, however, that the $2 \mathrm{D}$ properties are preserved as far as possible. This is the case in applications involving storage: fuel-gas storage (e.g., $\mathrm{H}_{2}$ ), or electro-chemical energy storage (supercapacitors or batteries [28]), require a large exposed surface per unit mass (or Specific Surface Area, SSA) to achieve a large gravimetric capacity (GC) [29], and the intrinsic capability of adsorbing specific substances (gas or electrolytes). Similar requirements are needed in catalysis applications [30]. Clearly, in this case the light weight of carbon and its intrinsic two-dimensionality are crucial, electric conductance is also needed in supercaps and batteries, while electronic properties can be an important added value. Finally, a number of applications related to coating can be considered as in between superficial and volumetric ones. In these, graphene-based materials must be deposited on a given surface in thin layers-but macroscopic on the atomic scale-to several purposes: protect from atmospheric agents [31], make it conductive [32] or hydrophobic [33], yet maintaining elasticity and resistance.

Indeed, preserving the needed properties and possibly enhancing or tailoring them in the 2D to 3D passage has turned out extremely complex. Up to now, two main routes were considered, both using graphene flakes as precursors. In the first, these are created by graphite exfoliation (usually after oxidation) and suspended in various solvents, resulting in a mixture of flakes with randomly distributed sizes and shapes; upon dehydration, they form 3D scaffolds with random structure and porosity [34]. These techniques, described in the next section, have the advantage of producing in cheap and scalable way a range of different 3D graphene-based nanoporous materials (GNM). The disadvantage is the high level of disorder, and the poor capability of controlling structural and mechanical properties, which are usually characterized a posteriori.

Building multi-layered structures separated by molecular "pillars" is considered an alternative to control the properties of the final 3D construct: theoretically, porosity and density in such structures are determined by the size and concentration of pillars, allowing the possibility of engineering the 3D structure via the pillar molecule design. Up to now, this route, has been followed using organic molecules as pillars $[35,36]$ coupled to suspended flakes, with encouraging but still not optimal results due to the difficulty of controlling the location of pillars on the randomly shaped flakes. The latest advances in this field are reviewed in Section 3.

Clearly, the optimal route should involve the control of the pillars positioning at the nano-scale on the precursor sheets, i.e., the combination of controlled chemical nano-patterning with the possibility of stacking the patterned multilayers in a controlled way. In Section 4 we illustrate the perspective to reach these objectives using the epitaxial graphene as precursor. A summary and conclusions follow in the last section.

\section{Graphene-Based Nano-Porous Materials: Production and Computer Modeling}

GNM are part of a broader class, the nano-porous carbons, which comprises activated carbons, carbide derived carbons, nanofoams and nanotubes, among others. While the synthesis of scaffolds with micrometer porosity has reached quite a high level of maturity thanks to the use of nano-to-micro particles as templates [37], strictly nano-porous GNMs are more difficult to produce with controlled structural characteristics. They are generally obtained with top-down techniques, using as precursors suspension of flakes. Flakes obtained from direct exfoliation of graphite (e.g., by liquid phase exfoliation [6,7]) have more regular structure and better conductive properties, and are therefore 
more suitable for electronics applications, but are also more expensive and difficult to obtain and handle. Therefore, for the 3D scaffold building, usually, the process starts from the oxidation of graphite to graphite oxide, e.g., by Hummer's method [38], followed by exfoliation-reduction either thermally [39], leading to Thermal Exfoliate Graphite Oxide (TEGO), or using microwaves, leading to Microwave Exfoliate Graphite Oxide (MEGO) [40,41], resulting in materials with SSA usually not exceeding $800 \mathrm{~m}^{2} / \mathrm{gr}[42,43]$. Samples can be subject to additional treatments, such as further reduction, or chemical activation (e.g., with $\mathrm{KOH}$ ), which modify the edges with the result of increasing the porosity to specific pore volume (SPV) greater than $2 \mathrm{~cm}^{3} / \mathrm{g}[30,44]$ and improving the SSA up or exceeding the graphene limit $\left(2630 \mathrm{~m}^{2} / \mathrm{g}\right)$. The result are 3D structures with randomly distributed $\mathrm{sp}^{2}$ areas interconnected to form a tangled scaffold with pores of size ranging in the nanometer scale (Figure 1). Overall, these materials display SSA values between 500 and $3500 \mathrm{~m}^{2} / \mathrm{g}$, maintaining good electrical conductivity, high mechanical strength and chemical stability $[45,46]$. The performances as gas absorbers are basically proportional to the SSA, reaching an excess $\mathrm{H}_{2}$ adsorption of $7 \%$ at $77 \mathrm{~K}$ [44]. The actual structural features, measured by SSA and PSV and some other additional parameters, such as the pore size distribution (PSD) and the mass density $\rho$ [47] (see Table 1), depend on all the phases of the production: the exfoliation process, determining the size and shape distribution of the flakes, the reduction, influencing the intrinsic perforation and defects of the flakes, and the activation, modifying the porosity and surfaces. Consequently, the gas adsorption could in principle be tuned provided a full control of the production process is possible.

The structure control is even more crucial when GNM are proposed as storage mean in electric or electrochemical form. Being a conductor with large surface, graphene could be used as a capacitor, whose capacitance can be largely increased adsorbing electrolytes, potentially making it a super-cap [40]. To this aim, besides the already mentioned SSA directly related to capacitance and improved by activation [48], also the intrinsic capability of adsorbing electrolytes or ionic liquids becomes a key feature [49]. Therefore, though the capacitance is generally inversely proportional to porosity, the pore sizes must also be optimized based on the size of the ionic species [50,51]. A fine tuning of the porosity can also produce ion desolvation and the consequent increase of efficiency via a pseudo-capacitance effect [52]. Similar properties are required to develop materials suitable for batteries. In particular, electric conductivity and chemical stability, besides porosity are the main requisites for the electrodes for lithium-based batteries [53,54]. Finally, GNM are attractive also as gas sorters or filters for environmental applications, e.g., water or air purification and $\mathrm{CO}_{2}$ sequestration [55].

In summary, the need for large GC for gas or electrolytes adsorption calls for large SSA and low $\rho[10,55]$, undermining the structural stability. On the other hand, volumetric capacity (VC) increases with $\rho$, and the pore size must be tuned to the adsorbed fluid [26]. Clearly, the capability of finely controlling the structural parameters has a main role [56]. This task is not only difficult, but also somehow ill-defined, since the experimental structural determinations of GNM are limited to the measurement of pair distribution functions (PDF) and average pore size or at most the PSD. Computer modeling and simulations have been called into play to compensate for the lack of detailed knowledge. However, the intrinsic disorder leaves quite a large amount of under-determinacy for model building. As a consequence, models including a degree of approximation or idealization are often used. The "perforated graphene" models [44] uses flat flakes not reconstructed at the edges and/or with regularly spaced pores [57]. Other studies are even simpler, including either the ideal slit-pore geometry [58-60] or defected [61]/rippled [62] multilayers. Finally, a number of models is based on periodic 3D structures, such as the open-carbon-frameworks $[63,64]$ or the carbon honeycomb [65].

While regular structures cannot allow a comprehensive throughput screening of the whole structural diversity landscape of GNM, clearly, the major issue in building realistic models for nanoporous scaffolds is their intrinsic disorder, difficult to include and needing large model systems to mild the effects of the boundaries or of the superimposed artificial periodicity of the model super cell. A number of computational approaches to generate disordered GNM model systems were adopted, differing in the description of the interactions between carbon atoms [66], and in the technique used to 
sample the structural parameters space. In the molecular dynamics (MD)-based techniques, atomistic empirical force fields (FF) are used to handle the interactions. These must be able to describe the different possible hybridization states of carbon based on the bond-order evaluated "on the fly" $[67,68]$ and/or the formation/dissociation of the different kinds of C-C bonds [69,70]. The model generation can then proceed "bottom up", starting from a random distribution of carbon atoms in gas phase, which are subsequently subject to molecular dynamics simulated annealing cycles (heating up to $10^{4} \mathrm{~K}$ and slow quenching [71]). Different structural morphologies can be obtained by changing the annealing conditions [72] (temperature, pressure [73] or density [74]), which is the simulation equivalent of changing the experimental conditions of production. This "from scratch" procedure is very computationally expensive, limiting the size of the model system to tens of nm, and preventing an extensive exploration of the structural parameters space and-consequently-a fine control over the resulting structures. A completely different point of view is taken in reverse Monte Carlo methods, where the atoms configurations are generated randomly and optimized until the simulated PDF matches the experimental one. In principle, the bare version of this method returns the best approximation of the inter-atomic interaction with a two-body potential as a side result, and structures compatible with it [75]. However, the nature of the C-C interaction is intrinsically many-body, therefore further restrains (geometric or energetic) are needed during the procedure [76]. This method is less expensive and can then generate larger model systems, giving good results in the meso-scale, but needs accurate structural determinations as input, which necessarily introduce an experimental bias.

To the aim of combining a modest computational effort with realism of the final model, a good strategy is using as precursors already formed graphene portions $[77,78]$ instead of atoms. On this road, a step forward was recently done using a model building algorithm that mimics the real synthesis [55,79]. The starting point is a mixture of flakes with size and shape distributed according to the experimentally known composition of the suspension. These are mixed to reproduce the real density and allow intersections. These, the edges and the perforations are then optimized using bond order or reactive FFs, and possibly functionalized with other species, mimicking the various experimental treatments. The system is finally refined by thermalizing MD cycles. The results realistically match the PDF and can be controlled by the starting concentration/size distribution/perforation of the flakes. Using already formed flakes as precursors, not only leads to more realistic structures, but also limits the computational effort allowing the generation and extensive study of large model systems. An overview of the available disordered GNM materials, models and their characteristics is reported in Figure 1 and Table 1.

Table 1. Disordered GNM and their structural characteristics.

\begin{tabular}{|c|c|c|c|c|c|c|}
\hline Precursor & Method/Treatment & SSA m ${ }^{2} / g$ & $\begin{array}{c}\text { PSV } \mathrm{cm}^{3} / \mathrm{g} \\
\text { or Avg Pore } \\
\text { Size }\end{array}$ & $\begin{array}{l}\text { Density } \\
\mathrm{cm}^{3} / \mathrm{g}\end{array}$ & $\begin{array}{c}\left.\mathrm{H}_{2} \text { Uptake (\% at } 77 \mathrm{~K}\right) \\
\text { or Capacitance }(\mathrm{F} / \mathrm{g})\end{array}$ & Ref. \\
\hline Graphite oxide & $\begin{array}{c}\text { TEGO, TEGO + } \\
\text { KOH }\end{array}$ & 2300 & & & $5 \%$ & 2015 [29] \\
\hline Graphite oxide & $\mathrm{TEGO}+\mathrm{KOH}$ & 3300 & 2.2 (PSV) & & $7 \%$ & 2015 [44] \\
\hline Graphite oxide & $\mathrm{TEGO}+\mathrm{KOH}$ & 2900 & 1.4 (PSV) & $\sim 1$ & $5.5 \%$ & $2015[78]$ \\
\hline Slit pores & Modelling & 5100 & 0.95 (PSV) & $\sim 1$ & $6.5 \%$ & $2015[78]$ \\
\hline Graphite & $\begin{array}{l}\text { plasma-induced } \\
\text { exfoliation }\end{array}$ & $\sim 800$ & $\sim 0.8 \mathrm{~nm}$ & & $2 \%$ & 2016 [79] \\
\hline Graphite-/diamond-like & $\begin{array}{l}\text { Heating/Quenching } \\
\text { MD simulations }\end{array}$ & $600-3000$ & 0-1.6 (PSV) & $0.5-3.5$ & & 2017 [72] \\
\hline activated carbon & Thermal treatment & 2220 & $0.67 \mathrm{~nm}$ & 1.95 & $5.5 \%$ & 2015 [47] \\
\hline Carbon atoms & $\begin{array}{l}\text { Quench MD } \\
\text { simulations }\end{array}$ & $\sim 1900$ & $3-15 \mathrm{~nm}$ & $\sim 0.9$ & $123 \mathrm{~F} / \mathrm{g}$ & 2019 [71] \\
\hline
\end{tabular}




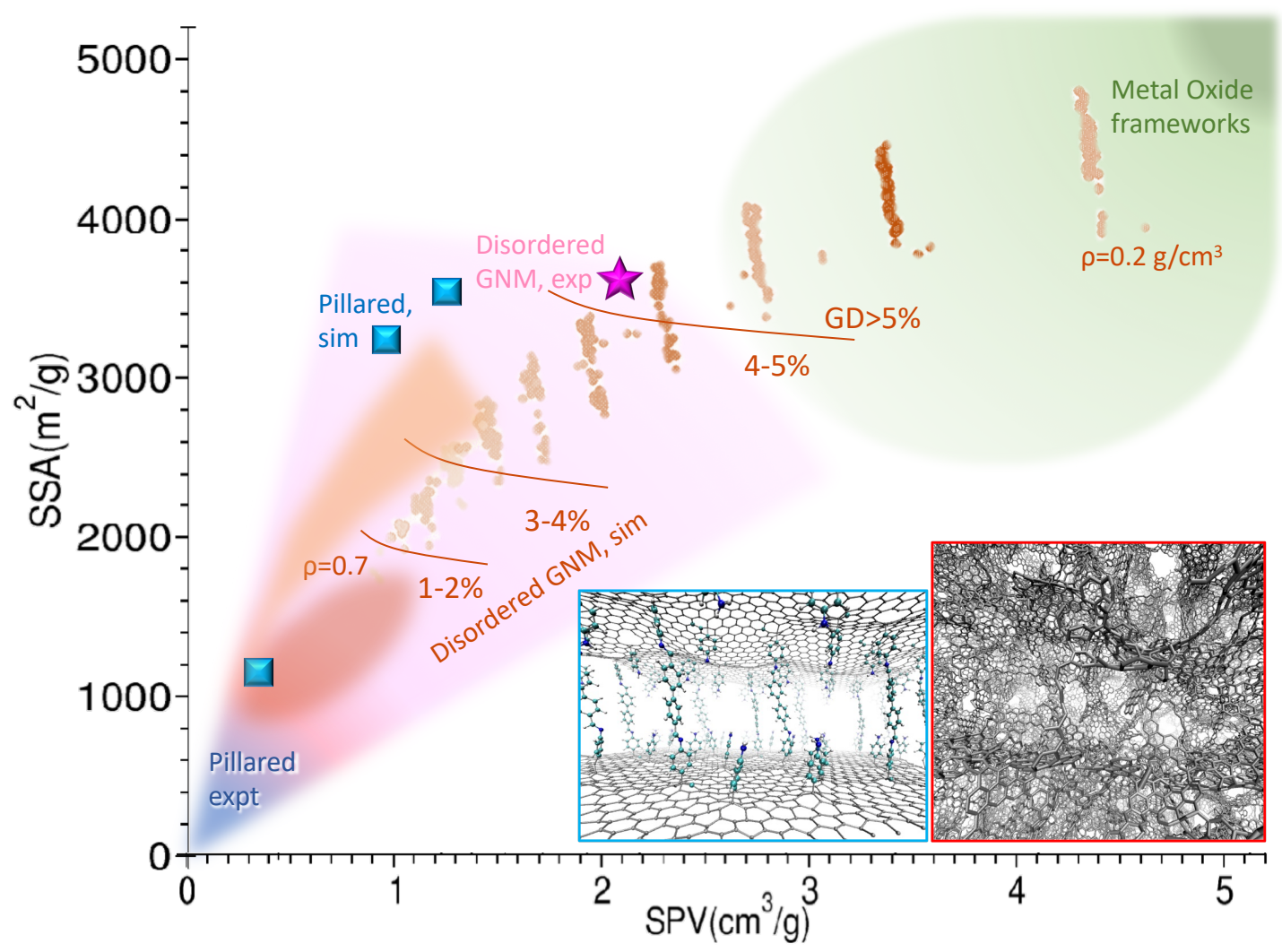

Figure 1. Structure diagram of graphene-based nanoporous materials (GNMs). The Specific Surface Area (SSA) vs specific pore volume (SPV) is reported for various experimental determinations and simulation studies. The blue shaded area encloses the experimental determinations of pillared structures, the one shaded in pink encloses the area spanned by experimental determinations of the disordered GNM scaffolds, both from various literature works cited in the text and in Table 2 (magenta star: Ref. [44]). The squared blue dots are simulations for pillared materials (Refs. [74,76,80]). Brown and reddish shades and dots are from simulations. The brown dots are preliminary from ref. [55], and roughly accumulates on lines at different decreasing density (smaller and larger simulated density are reported); red oval shade and orange shade are extracted and processed from ref. [74]. The brown lines separate areas at increasing excess GD evaluated at 77K. The region typically spanned by the Metal Oxide Frameworks is reported in green. Sample structures for the pillared (blue border) and disordered GNM (red border) are reported as insets.

\section{Pillared Materials: State of the Art and Open Problems}

In disordered nanoporous materials the porosity of the final structures depends on how the flakes interlace during all the phases of the preparation, which introduces a high degree of disorder and stochasticity. In order to reduce this issue and improve the control over the outcome, the idea rose of synthesizing layered structures separated by molecular pillars, i.e., organic molecules suitably designed with given lengths, rigidity and possibly other physic-chemical properties. The size of the pillars determines the inter-layer spacing, and controls the average pore size, together with the relative distance of the pillars on the sheets. The first realization of such structures traces back to almost two decades ago when, inspired by metal-organic frameworks chemistry, layered structures separated by diboronic acid molecules were first proposed [81]. The pillars adhesion exploited the reactivity of hydroxy groups of graphene oxide (GO) with the acidic groups, leading to $\mathrm{GO}$ frameworks (GOF). These were subsequently characterized via Xray diffraction and neutron scattering, and tested through their $\mathrm{H}_{2}$ adsorption capability, whose low value indicates rather a small SSA value (hundreds $\mathrm{of}^{2} / \mathrm{g}$ ). The synthesis procedure was recently optimized [34], obtaining values of SSA up to $\sim 600 \mathrm{~m}^{2} / \mathrm{g}$ and pores size up to $2 \mathrm{~nm}$. At the same time, it was shown that in some cases, in polar solvents these 
material exhibits reversible swelling, posing doubts on the complete covalent nature of the layer linkage [35]. Using as pillars di-amine of different lengths [82] resulted in materials with tuneable interlayer distance in the range $0.8-1.1 \mathrm{~nm}$, generally hydrophilic and insulating. In fact, ab initio calculations with simplified model systems demonstrated that achieving electric conductivity in these materials is not easy, due to the rupture of the aromaticity at the linkage sites [80].

The optimization of these materials depends on their use: for electric energy storage, both a finely tuned pore size and the conductivity are important. Therefore different synthesis routes were explored, involving reduction of GO, either ex post [83] or directly starting from reduced GO (rGO); in the latter case, most of the proposed reaction exploit the chemistry of diazonium salts radicals, selectively reacting with the defective sites of rGO [84-86]. Among the best performances in terms of SSA where obtained with a two-step procedure: the rGO was first functionalized with benzoic acid [85], obtaining a layered material with good porosity, but scarce conductivity. Polyaniline was subsequently synthesised in situ obtaining a composite material with larger average inter-layer distance though smaller average pore size, and with improved electric conductance. Alternative routes to tailor inter-layer distance and porosity involve cross-linking by aryl-aryl reaction of rGO functionalized with iodo-phenyls [86] or $\mathrm{Zn}+$ coordination of rGO functionalized with azobenzoic acid [87]. A summary of the recent literature on experimental and theoretical structural determinations of these materials is reported in Table 2. The main structural characteristics are also reported in Figure 1.

Table 2. Pillared materials derived by Graphite Oxide (GO) or reduced GO (rGO) flakes and their structural characteristics.

\begin{tabular}{|c|c|c|c|c|c|c|}
\hline Precursor & Pillars & Reaction/Method & $\mathrm{SSA} \mathrm{m}^{2} / \mathrm{g}$ & Structural Features & $\begin{array}{l}\mathrm{H}_{2} \text { Uptake }(\% \\
\text { at } 77 \mathrm{~K})\end{array}$ & Ref. \\
\hline GO & Diboronic acid & $\begin{array}{l}\text { Solvothermal } \\
\text { Acid+OH } \\
\text { dehydration }\end{array}$ & $\sim 200$ & $\begin{array}{l}\sim 11 \AA \text { interlayer spacing; } \\
\text { pillars distance: } 7-8 \AA\end{array}$ & $\begin{array}{l}1 \% \text { experiment } \\
5 \% \text { simulation }\end{array}$ & 2010 [80] \\
\hline GO & Diboronic acid & Solvothermal & $500-600$ & $\begin{array}{l}\text { Interlayer: } 8-15 \text { (swelling) } \\
\text { Pore size }>2 \mathrm{~nm}\end{array}$ & $\sim 1.5 \%$ & 2015 [34] \\
\hline GO & "tetrapod" amine & Solvothermal & $>660$ & $\begin{array}{l}\text { Interlayer: } 10-13 \text { to } \sim 16 \AA \\
\text { (swelling) }\end{array}$ & $\sim 1.5 \%$ & 2017 [35] \\
\hline GO & $\begin{array}{l}\text { Different types of } \\
\text { diamine }\end{array}$ & $\begin{array}{l}\text { Cross-linking, } \\
\text { thermally promoted }\end{array}$ & & $\begin{array}{c}\text { Interlayer } 8.5-11 \AA \\
\text { Pillar dist } \sim 10 \AA\end{array}$ & & 2019 [84] \\
\hline GO reduced & 1-6 diaminohexane & Cross-linking & $150-200$ & $\begin{array}{c}\text { Inter layer: } 7.8 \AA \\
\text { Pore size: } 1 \mathrm{~nm}, 15 \mathrm{~nm}\end{array}$ & & 2018 [85] \\
\hline rGO & $\begin{array}{l}\text { Aryl bis-diazionium } \\
\text { salts (and variants) }\end{array}$ & Radical reaction & $200-400$ & $\begin{array}{l}\text { Interlayer: } 5-10 \AA \\
\text { inter-pillar ext: } \sim 5 \AA\end{array}$ & & 2016 [86] \\
\hline rGO & $\begin{array}{l}\text { 4-iodophenyl } \\
\text { diazionium salts }\end{array}$ & $\begin{array}{l}\text { Aryl-aryl coupling } \\
\text { reaction for } \\
\text { cross-linking }\end{array}$ & & Pore size $1-10 \mathrm{~nm}$ & & 2015 [88] \\
\hline rGO & $\begin{array}{c}\text { Azobenzoic } \\
\text { acid-based ligands }\end{array}$ & $\begin{array}{l}\mathrm{Zn}^{2+} \text { coordination for } \\
\text { cross-linking }\end{array}$ & & $\begin{array}{l}\text { inter-layer distance } \sim 3 \mathrm{~nm} \\
\text { in the hydrogel }\end{array}$ & & 2012 [89] \\
\hline graph & $\begin{array}{l}\text { Diboronic acid } \\
\text { variants }\end{array}$ & $\begin{array}{l}\text { Density Functional } \\
\text { Theory, Tight binding }\end{array}$ & & $\begin{array}{l}\text { Interlayer } 1.1-2.2 \mathrm{~nm} \\
\text { inter pillar } 3-5 \AA\end{array}$ & $1.5 \%$ & 2019 [84] \\
\hline graph & nanotubes & $\begin{array}{l}\text { Density Functional } \\
\text { Theory, Grand } \\
\text { Canonical MC }\end{array}$ & & $\begin{array}{l}1.2 \mathrm{~nm} \text { interlayer, } \\
1.5 \mathrm{~nm} \text { inter-pillar }\end{array}$ & $6 \%$ & $\begin{array}{c}2017 \\
{[71,72]}\end{array}$ \\
\hline GO, gr & $\begin{array}{l}\text { Organic aromatic } \\
\text { pillars }\end{array}$ & $\begin{array}{c}\text { Reax FF } \\
\text { Grand Canonical MC }\end{array}$ & & $\begin{array}{l}\text { Pore size } 0.8,1,1.1 \mathrm{~nm} \\
\text { Inter-layer } \sim 3 \mathrm{~nm}\end{array}$ & $\sim 4 \%$ & $\begin{array}{c}2017 \\
{[73,74]}\end{array}$ \\
\hline
\end{tabular}

Although steps forward have been done in the control of the functionalization, the performances of these materials are not better than those of disordered GNM: SSA is at best several hundreds, far below the theoretical limits and below the simulation predictions. In fact, both the carbon-only model systems including nanotube-pillars [88,89] and the molecular-pillared model systems [81,90], display, in simulations, GD uptake (and SSA) 5-10 times larger than the measured ones, besides the theoretical capability of efficient gas sorting [91], desalinization [92], and interesting mechanical properties [93]. 
Although the origin of the theory-experiment discrepancy is not clear, it was shown that ideal structures with nearly flat sheets and regularly spaced pillars display a better performances in simulations [84], and that the adsorption performances depend on the fine tuning of the pillars distance, which must be large enough to allow the molecules access and hosting in a layer on the surface, but not too large, in order to maximize the GD. Therefore, a regular and controlled patterning seems the key for obtaining highly performing pillared materials.

\section{Multilayers from Epitaxy: A Perspective}

The reason why the pillars distribution is poorly controllable is encoded in the use of GO (or rGO) flakes as precursors: the covalent bonding of pillars or anchors exploits the presence of epoxy/hydroxy groups or defects, which are reactive sites [94]. However, these are randomly distributed, and their concentration is variable, and not easily tailorable [95]. In addition, flakes edges are also very reactive, attracting a relatively large number of functional groups, which introduces further disorder in the structure. Finally, the environmental conditions that promote the reaction (temperature, solvent, etc.) can favor aggregation in an almost unpredictable way. From this point of view, using epitaxial graphene as precursor would in principle bring some advantage, mainly related to the regularity of the material and to its laying on an extended solid support. In fact, this would allow a direct control over functionalization and check of results e.g., with atomic resolved microscopy techniques. One popular technique to produce supported graphene is chemical vapor deposition of carbon-rich compounds over metal substrates (after their cracking) [96]. Alternatively, one can use carbon rich substrates, such as $\mathrm{SiC}$, and let the carbon layers reconstruct in the honeycomb lattice by selective evaporation of $\mathrm{Si}$ from surfaces with specific symmetries [97]. In both cases, one obtains macroscopic almost defectless single layers. In general, perfect graphene is poorly reactive, because of its fully delocalized stable $\mathrm{sp}^{2}$ electronic system. Clearly, reactivity can be brought back by reintroducing defects, e.g., by nitrogen sputtering [98], which creates either substitutional or structural defects, proven to act as seeds for adhesion of metal clusters or hydrogen [99]. However, these defects are introduced randomly, pushing back to the same problems as in GO flakes.

Indeed, specific kinds of epitaxial graphene offer different possibilities, which exploit the interaction with the substrate. For instance, radicals of diazonium salts are able to attach to $\mathrm{sp}^{2}$ sites but manifests a preference for graphene on hydrophilic substrates [100], due to charge accumulation effects. A similar effect is observed for graphene on metals such as iridium or ruthenium [101,102], where, in addition, a spatially modulated reactivity is created following the nano-metric moiré pattern of corrugation. This open the road to substrate driven functionalization, with the possibility of creating chemical nano-patterns following the symmetry of the moiré superlattice. Similar effects were obtained by intercalating metal clusters in between graphene and an insulating substrate [103], where the preferential adhesion of the radicals was observed in proximity of the metal cluster. The enhancement of reactivity (towards aryl radicals) is also observed on non-metallic substrates, such as patterned $\mathrm{SiO}_{2}$ [104] and on the protruding areas of the natural moiré corrugation lattice of monolayer graphene on $\mathrm{SiC}$ (towards atomic hydrogen [26]). In these cases, it is attributed to the curvature [24]. In fact, both rippling and strain [105] produce charge inhomogeneities. Therefore, supported graphenes with moiré patterns are very promising materials for substrate driven regular nano-patterning.

We now focus on graphene on $\mathrm{SiC}$, to further explore this concept. It is important to observe that graphene on $\mathrm{SiC}$ is not a single material but includes different types of 2D carbons [106] that can be obtained with different procedures (see Figure 2a). Upon Si evaporation from the Si-rich surfaces with hexagonal symmetry, excess carbon produces in the first instance a hexagonal carbon buffer layer (BL) [107], covalently bound to the substrate, and partially $\mathrm{sp}^{3}$ hybridized. The bonds and corrugations follow a moiré pattern, due to the mismatch of the two lattices, displaying a hexagonal super-lattice of $\sim 3.2 \mathrm{~nm}$ side, made of sharp crests and peaks with $\mathrm{sp}^{3}$-like pyramidal configuration [15]. Fully $\mathrm{sp}^{2}$ graphene can be obtained continuing evaporation: another BL forms under the first one, which is detached and becomes the so-called Mono-Layer graphene (MLG), characterised by a corrugation 
pattern with the same symmetry as BL, though smother [108]. Alternatively, the BL can be detached by intercalating $H$ [108] or metals [109], obtaining the Quasi-Free-Standing Monolayer graphene (QFMLG) [110]. This is ideally flat, but displays in reality localized concavities, occupying the sites of a lattice roughly corresponding to $6 \times 6$ of $\mathrm{SiC}$ [111] with $\sim 1.8 \mathrm{~nm}$ side, which were associated with vacancies of $\mathrm{H}$ in the intercalating layer [112]. The electronic structure is strongly affected by these defects, since Si dangling bonds produce electronic states localized near the Fermi level [113].
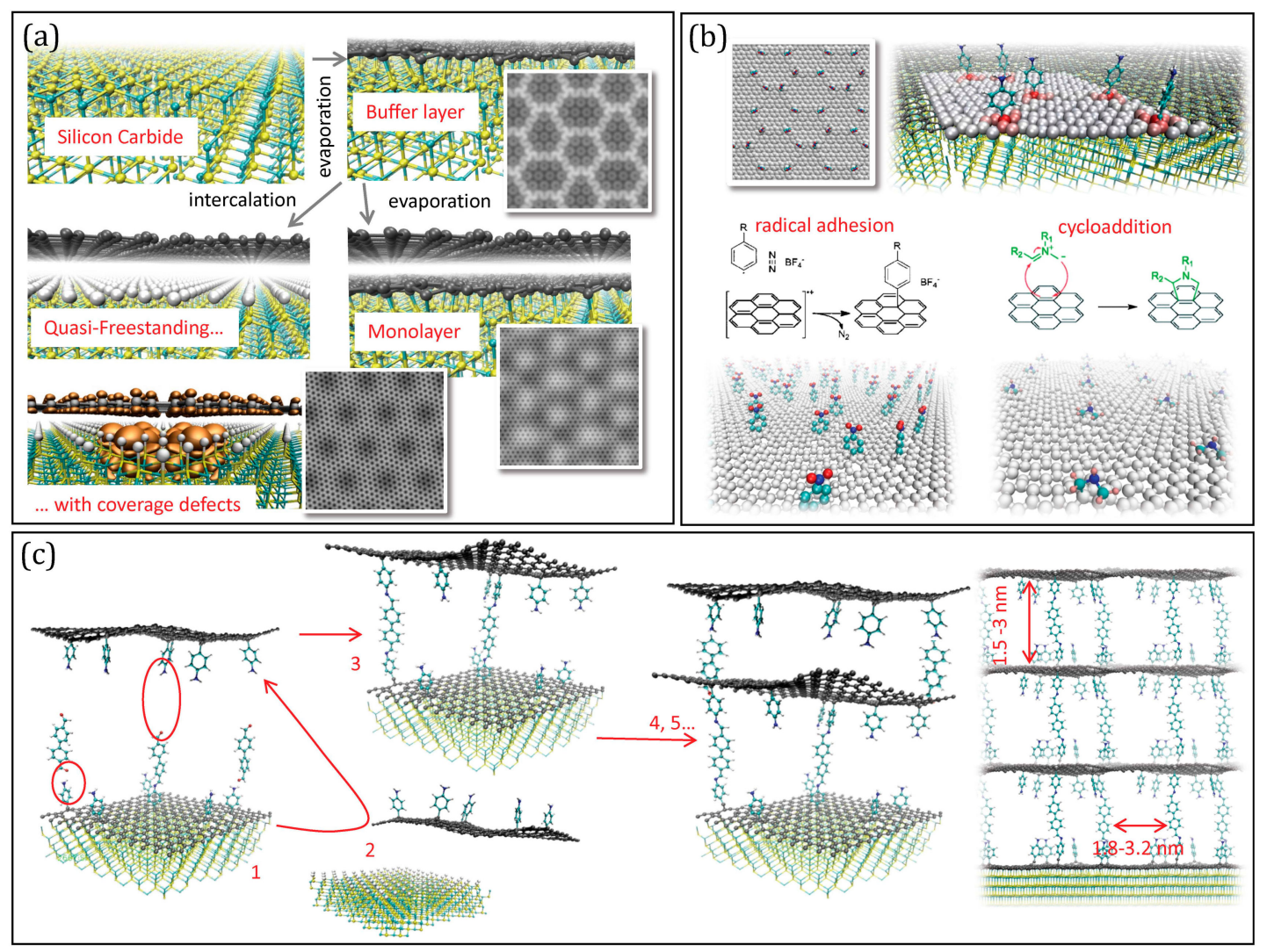

Figure 2. (a) Summary of the production of graphenes on $\mathrm{SiC}$ : the Buffer layer (BL by evaporation of $\mathrm{Si}$ ), graphene monolayer (GML by subsequent evaporation) and quasi-free-standing monolayer (QFMLG, by intercalation of $\mathrm{H}$ or metal). The simulated Scanning Tunnel Microscopy images are reported for the BL, for the ML and for the QFSML with defects in the intercalation coverage layer. (b) Scheme of possible functionalization reactions exploiting the corrugation pattern of the BL. (c) Scheme of a possible strategy to build pillared multilayers: after pillaring (1), the cross-linking should occur with a previously detached functionalized sheet $(2$ to 3$)$, and be re-iterated $(4,5 \ldots)$ to give a regular structure.

While all of the different carbon layers on $\mathrm{SiC}$ display charge inhomogeneities following a regular nano-pattern induced by the interaction with the substrate, either mediated by the hybridization, by the corrugation or by the vacancies in the intercalation coverage, only the GML was tested on its reactivity, showing selective $\mathrm{H}$ adhesion on the crests [26]. On the other hand, the localised electronic states forming on the QFMLG in corresponding of H-vacancies have various sizes and shapes, depending on the number and relative location of vacant sites and their energy is organized in groups of levels near the Fermi energy [113], indicating a possible propensity to electrophile attack. Even more interesting from the functionalization is the buffer layer (Figure 2b) since it displays the strongest deviation from graphene symmetry and the sharper definition of the moiré pattern [15]. Specifically, the $\mathrm{sp}^{3}$ cusps at the vertices of the moiré super-lattice are likely to be highly reactive sites in general, not only towards radicals, but possibly also towards e.g., dissociative chemisorption of $\mathrm{H}_{2}$. Conversely, the protruding crests, organized in diene like structures, and the intruding areas, 
organized in "benzene-like" rings [15] are likely to be attractive for cyclo-addition reactions [114], leading to a spatially complementary selectivity.

Clearly, the BL functionalization should be viewed as the first, yet fundamental, step of a procedure involving the multilayer formation (see Figure 2c): once the molecular anchors are attached, pillars of different length can be added exploiting, e.g., solvothermal de-hydration reactions; subsequently the layer should be exposed to similarly functionalised layers (previously detached by the substrate by intercalation) which have to be stacked and cross-linked. These steps are also taken in the already realized synthesis of pillared materials from GO or rGO flakes [90-99]. However, using regularly patterned precursors would offer two unique advantages: first, the space matching of cross-linking groups can potentially trigger the self-assembly of the sheets, greatly impring the efficiency of the process, and second, the final result would be a structure with pillars at controlled distance in the range of 2-3 nm. This, together with the inter-layer distance controlled by the pillar length, will result in a structure with pre-determined porosity. Clearly, exploring experimentally this strategy would benefit of preliminary computer simulations, which are currently work in progress.

\section{Summary, Conclusions and Possible Developments}

In summary, we have reported three possible routes to produce graphene-based materials with porosity on the nano-scale, ordered by increasing capability of control and tailoring of the final structure. The first class produces the disordered nanoporous scaffolds from GO or rGO flakes. These can reach large values of SSA and are, up to now, the most interesting for gas storage. However, controlling their final structure is not straightforward, because of the disordered structure of the precursors and of the stochastic nature of their combination during the production procedure. With the aim of controlling at least a part of the variables determining the porosity, the second strategy introduces on the flakes pillars molecules with pre-determined lengths and shapes. This produces a class of materials with average pore sizes at the nano-metric scale, matching with the size of electrolytes and therefore suitable for the use in electric and electro-chemical storage. However, the average value of the SSA of these materials is rather low, and the poor control over the distribution of the pillars on the sheet introduces disorder, preventing a full optimization, not only for supercapacitors and batteries, but also in catalysis and filtering applications.

A third route is currently in its infancy, which would provide a full control over the distribution and location of the pillars. This considers as precursors epitaxial graphene and exploits the electronic inhomogeneities of the sheet produced by the interaction with the substrate, typically following a nano-metric moiré pattern, for the controlled chemical functionalization. Although the first timid steps (selective functionalization with atoms or small molecules) were demonstrated, the way is long towards the production of multi-layers.

The support of computer modeling and simulations is essential in all cases: in the case of disordered scaffolds, the main issue is to create realistic models and to understand the relationship between production procedure and final structure, and between the latter and the adsorption performances; for the pillared (r) GO materials, the challenge is to control the concentration and location of the pillars and predict the properties as a function of the used pillar. Most of all, computer modeling will be of outmost importance in the pillared multi-layers building from epitaxial graphene. In this case, the simulation of the pillaring, stacking and cross-linking would be essential to give indications for the experimental realization of the procedure. Though extremely challenging, this strategy might give a full control over all the structural features of the resulting structure, and-acting on the nature of pillars-might allow to create brand new materials with tailored and unprecedented properties, such as locally tuned elasticity or conductivity, reactivity to external fields, optical response, and others.

Funding: This research was funded by EU-H2020, Graphene-Core1 (agreement No. 696656) and Core2 (agreement No. 75219), MCSA (agreement No. 657070), by CINECA awards IsB11_flexogra (2015), IsC36_ElMaGRe (2015), IsC44_QFSGvac (2016), IsC44_ReIMCGr (2016), IsC61_MGchpDFA (2018) IsC69_EFaRe (2019), IsB19_DiNaGra (2019) and PRACE “Tier0” award Pra13_2016143310 (2016). 
Acknowledgments: We thank Stefan Heun, Paolo Giannozzi, Camilla Coletti, Yuya Murata, and Vittorio Pellegrini for useful discussions.

Conflicts of Interest: The authors declare no conflict of interest.

\section{References}

1. Geim, A.K.; Novoselov, K.S. The rise of graphene. Nat. Mater. 2007, 6, 183-191. [CrossRef] [PubMed]

2. Castro Neto, A.H.; Guinea, F.; NMRPeres Novoselov, K.S.; Geim, A.K. The electronic properties of graphene. Rev. Mod. Phys. 2009, 81, 109. [CrossRef]

3. Lee, C.; Wei, X.; Kysar, J.W.; Hone, J. Measurement of the Elastic Properties and Intrinsic Strength of Monolayer Graphene. Science 2008, 321, 385. [CrossRef] [PubMed]

4. Camiola, V.D.; Farchioni, R.; Pellegrini, V.; Tozzini, V. Hydrogen transport within graphene multilayers by means of flexural phonons. 2D Mater. 2015, 2, 014009. [CrossRef]

5. Fasolino, A.; Los, J.H.; Katsnelson, M.I. Intrinsic ripples in graphene. Nat. Mater. 2007, 6, 858-861. [CrossRef] [PubMed]

6. Bonaccorso, F.; Colombo, L.; Yu, G.; Stoller, M.; Tozzini, V.; Ferrari, A.C.; Ruoff, R.S.; Pellegrini, V. Graphene, related two-dimensional crystals, and hybrid systems for energy conversion and storage. Science 2015, 347, 1246501. [CrossRef]

7. Sun, P.; Wang, K.; Zhu, H. Recent Developments in Graphene-Based Membranes: Structure, Mass-Transport Mechanism and Potential Applications. Adv. Mater. 2016, 28, 2287-2310. [CrossRef]

8. Büch, H.; Rossi, A.; Forti, S.; Convertino, D.; Tozzini, V.; Coletti, C. Superlubricity of epitaxial monolayer WS2 on graphene. Nano Res. 2018, 11, 5946-5956. [CrossRef]

9. Chee, W.K.; Lim, H.N.; Zainal, Z.; Huang, N.M.; Harrison, I.; Andou, Y. Flexible Graphene-Based Supercapacitors: A Review. J. Phys. Chem. C 2016, 120, 4153-4172. [CrossRef]

10. Mahmoudi, T.; Wang, Y.; Hahn, Y.-B. Graphene and its derivatives for solar cells application. Nano Energy 2018, 47, 51-65. [CrossRef]

11. Denis, P.A.; Huelmo, C.P. Martins AS Band Gap Opening in Dual-Doped Monolayer Graphene. J. Phys. Chem. C 2016, 120, 13. [CrossRef]

12. Iyakutti, K.; Kumar, E.M.; Lakshmi, I.; Thapa, R.; Rajeswarapalanichamy, R.; Surya, V.J.; Kawazoe, Y. Effect of surface doping on the band structure of graphene: A DFT study. J. Mater. Sci. 2016, 27, 2728-2740. [CrossRef]

13. Deng, S.; Berry, V. Wrinkled, rippled and crumpled graphene: An overview of formation mechanism, electronic properties, and applications. Mater. Today 2016, 19, 197-212. [CrossRef]

14. Zaminpayma, E.; Emami Razavi, M.; Nayebi, P. Electronic properties of graphene with single vacancy and Stone-Wales defects. Appl. Surf. Sci. 2017, 31, 101-106. [CrossRef]

15. Nair, M.N.; Palacio, I.; Celis, A.; Zobelli, A.; Gloter, A.; Kubsky, S.; Turmaud, J.-P.; Conrad, M.; Berger, C.; de Heer, W.; et al. Band Gap Opening Induced by the Structural Periodicity in Epitaxial Graphene Buffer Layer. Nano Lett. 2017, 174, 2681-2689. [CrossRef]

16. Cavallucci, T.; Tozzini, V. Intrinsic structural and electronic properties of the Buffer Layer on Silicon Carbide unraveled by Density Functional Theory. Sci. Rep. 2018, 8, 13097. [CrossRef]

17. Loh, K.P.; Tong, S.W.; Wu, J. Graphene and Graphene-like Molecules: Prospects in Solar Cells. J. Am. Chem. Soc. 2016, 138, 1095-1102. [CrossRef]

18. Cohen-Tanugi, D.; Lin, D.-C.; Grossman, J.C. Multilayer Nanoporous Graphene Membranes for Water Desalination. Nano Lett. 2016, 16, 1027-1033. [CrossRef]

19. Guinea, F.; Katsnelson, M.I.; Geim, A.K. Energy gaps and a zero-field quantum Hall effect in graphene by strain engineering. Nat. Phys. 2010, 6, 30. [CrossRef]

20. Hicks, J.; Tejeda, A.; Taleb-Ibrahimi, A.; Nevius, M.S.; Wang, F.; Shepperd, K.; Palmer, J.; Bertran, F.; Le Fèvre, P.; Kunc, J.; et al. A wide-bandgap metal-semiconductor-metal nanostructure made entirely from graphene. Nat. Phys. 2012, 9, 49. [CrossRef]

21. Rossi, A.; Piccinin, S.; Pellegrini, V.; de Gironcoli, S.; Tozzini, V. Nano-Scale Corrugations in Graphene: A Density Functional Theory study of Structure, Electronic Properties and Hydrogenation. J. Phys. Chem. C 2015, 119, 7900. [CrossRef]

22. McKay, H.; Wales, D.J.; Jenkins, S.J.; Verges, J.A.; de Andres, P.L. Hydrogen on graphene under stress: Molecular dissociation and gap opening. Phys. Rev. B 2010, 81, 075425. [CrossRef] 
23. Goler, S.; Coletti, C.; Tozzini, V.; Piazza, V.; Mashoff, T.; Beltram, F.; Pellegrini, V.; Heun, S. Influence of Graphene Curvature on Hydrogen Adsorption: Towards Hydrogen Storage Devices. J. Phys. Chem. C 2013, 117, 11506. [CrossRef]

24. Boukhvalov, D.W.; Son, Y.-W. Covalent Functionalization of Strained Graphene. Chem. Phys. Chem. 2012, 13, 1463. [CrossRef]

25. Wang, Z.F.; Zhang, Y.; Liu, F. Formation of hydrogenated graphene nanoripples by strain engineering and directed surface self-assembly. Phys. Rev. B 2011, 83, 041403(R). [CrossRef]

26. Cavallucci, T.; Kakhiani, K.; Farchioni, R.; Tozzini, V. Morphing Graphene-Based Systems for Applications: Perspectives from Simulations. In GraphITA Carbon Nanostructures; Springer: Cham, Switzerland, 2017; pp. 87-111.

27. Camiola, V.D.; Farchioni, R.; Cavallucci, T.; Rossi, A.; Pellegrini, V.; Tozzini, V. Hydrogen storage in rippled graphene: Perspectives from multi-scale simulations. Front. Mater. 2015, 2, 3. [CrossRef]

28. Quesnel, E.; Roux, F.; Emieux, F.; Faucherand, P.; Kymakis, E.; Volonakis, G.; Giustino, F.; Martín-García, B.; Moreels, I.; Gürsel, S.A.; et al. Graphene-based technologies for energy applications, challenges and perspectives. 2D Mater. 2015, 2, 030204. [CrossRef]

29. Klechikov, A.G.; Mercier, G.; Merino, P.; Blanco, S.; Merino, C.; Talyzin, A.V. Hydrogen storage in bulk graphene-related materials. Micropor. Mesopor. Mater. 2015, 210, 46-51. [CrossRef]

30. Qiu, B.; Xing, M.; Zhang, J. Recent advances in three-dimensional graphene based materials for catalysis applications. Chem. Soc. Rev. 2018, 47, 2165. [CrossRef]

31. Bustillos, J.; Zhang, C.; Boesl, B.; Agarwal, A. Three-Dimensional Graphene Foam-Polymer Composite with Superior Deicing Efficiency and Strength. ACS Appl. Mater. Interfaces 2018, 10, 5022-5029. [CrossRef]

32. Neves, A.I.S.; Rodrigues, D.P.; De Sanctis, A.; Alonso, E.T.; Pereira, M.S.; Amaral, V.S.; Melo, L.V.; Russo, S.; de Schrijver, I.; HAlves, M.F. Craciun Towards conductive textiles: Coating polymeric fibres with graphene. Sci. Rep. 2017, 7, 4250. [CrossRef] [PubMed]

33. Zheng, Z.; Liu, Y.; Bai, Y.; Zhang, J.; Han, Z.; Ren, L. Fabrication of biomimetic hydrophobic patterned graphene surface with ecofriendly anti-corrosion properties for $\mathrm{Al}$ alloy. Coll. Surf. A Physicochem. Eng. Asp. 2016, 500, 64-71. [CrossRef]

34. Xu, Y.; Sheng, K.; Li, C.; Shi, G. Self-assembled graphene hydrogel via a one-step hydrothermal process. ACS Nano 2010, 4, 4324. [CrossRef]

35. Mercier, G.; Klechikov, A.; Hedenstroöm, M.; Johnels, D.; Baburin, I.A.; Seifert, G.; Mysyk, R.; Talyzin, A.V. Porous Graphene Oxide/Diboronic Acid Materials: Structure and Hydrogen Sorption. J. Phys. Chem. C 2015, 119, 27179-27191. [CrossRef]

36. Sun, J.; Morales-Lara, F.; Klechikov, A.; Talyzin, A.V.; Baburin, A.; Seifert, G.; Cardano, F.; Baldrighi, M.; Frasconi, M.; Giordani, S. Porous graphite oxide pillared with tetrapod-shaped molecules. Carbon 2017, 120, 145-156. [CrossRef]

37. Liang, C.; Li, Z.; Dai, S. Mesoporous carbon materials: Synthesis and modification. Angew. Chem. Int. Ed. 2008, 47, 3696-3717. [CrossRef] [PubMed]

38. Talyzin, A.V.; Mercier, G.; Klechikov, A.; Hedenström, M.; Johnels, D.; Wei, D.; Cotton, D.; Moons, A.E. Brodie vs Hummers graphite oxides for preparation of multi-layered materials. Carbon 2017, 115, 430-440. [CrossRef]

39. Talyzin, A.V.; Szabó, T.; Dékány, I.; Langenhorst, F.; Sokolov, P.S.; Solozhenko, V.L. Nanocarbons by High-Temperature Decomposition of Graphite Oxide at Various Pressures. J. Phys. Chem. C 2009, 113, 11279-11284. [CrossRef]

40. Zhu, Y.; Murali, S.; Stoller, M.D.; Ganesh, K.J.; Cai, W.; Ferreira, P.J.; Pirkle, A.; Wallace, R.M.; Cychosz, K.A.; Thommes, M.; et al. Carbon-based supercapacitors produced by activation of graphene. Science 2011, 332, 1537-1541. [CrossRef]

41. Zhu, Y.; Murali, S.; Stoller, M.D.; Velamakanni, A.; Piner, R.D.; Ruoff, R.S. Microwave assisted exfoliation and reduction of graphite oxide for ultracapacitors. Carbon 2010, 48, 2118-2122. [CrossRef]

42. Zhang, C.; Lv, W.; Xie, X.; Tang, D.; Liu, C.; Yang, Q.-H. Towards low temperature thermal exfoliation of graphite oxide for graphene production. Carbon 2013, 62, 11-24. [CrossRef]

43. Kovtun, A.; Treossi, E.; Mirotta, N.; Scidà, A.; Liscio, A.; Christian, M.; Valorosi, F.; Boschi, A.; Young, R.J.; Galiotis, C.; et al. Benchmarking of graphene-based materials: Real commercial products versus ideal graphene. 2D Mater. 2019, 6, 025006. [CrossRef] 
44. Klechikov, A.; Mercier, G.; Sharifi, T.; Baburin, I.A.; Seifert, G.; Talyzin, A.V. Hydrogen storage in high surface area graphene scaffolds. Chem. Comm. 2015, 51, 15280-15283. [CrossRef] [PubMed]

45. Raccichini, R.; Varzi, A.; Passerini, S.; Scrosati, B. The role of graphene for electrochemical energy storage. Nature Mater. 2015, 14, 271-279. [CrossRef] [PubMed]

46. Chen, K.; Song, S.; Li, F.; Xue, D. Structural design of graphene for use in electrochemical energy storage devices. Chem. Soc. Rev. 2015, 44, 6230-6257. [CrossRef] [PubMed]

47. Minuto, F.D.; Policicchio, A.; Aloise, A.; Agostino, R.G. Liquid-like hydrogen in the micropores of commercial activated carbons. Int. J. Hydrog. Energy 2015, 40, 14562-14572. [CrossRef]

48. Nomura, K.; Nishihara, H.; Kobayashi, N.; Asada, T.; Kyotani, T. 4.4 V supercapacitors based on super-stable mesoporous carbon sheet made of edge-free graphene walls. Energy Environ. Sci. 2019, 12, 1542-1549. [CrossRef]

49. Tsai, W.-Y.; Lin, R.; Murali, S.; Zhang, L.; McDonough, J.K.; Ruoff, R.S.; Taberna, P.-L.; Gogotsi Yu Simon, P. Outstanding performance of activated graphene based supercapacitors in ionic liquid electrolyte from -50 to $80{ }^{\circ} \mathrm{C}$. Nano Energy 2013, 2, 403-411. [CrossRef]

50. Méndez-Morales, T.; Ganfoud, N.; Li, Z.; Haefele, M.; Rotenberg, B.; Salanne, M. Performance of microporous carbon electrodes for supercapacitors: Comparing graphene with disordered materials. Energy Storage Mater. 2019, 17, 88-92. [CrossRef]

51. Kondrat, S.; Kornyshev, A.A. Pressing a spring: What does it take to maximize the energy storage in nanoporous supercapacitors? Nanoscale Horiz. 2016, 1, 45-52. [CrossRef]

52. Salanne, M.; Rotenberg, B.; Naoi, K.; Kaneko, K.; Taberna, P.-L.; Grey, C.P.; Dunn, B.; Simon, P. Efficient storage mechanisms for building better supercapacitors. Nat. Energy 2016, 1, 16070. [CrossRef]

53. Huang, J.-Q.; Zhuang, T.-Z.; Zhang, Q.; Peng, H.-J.; Chen, C.-M.; Wei, F. Permselective Graphene Oxide Membrane for Highly Stable and Anti-Self-Discharge Lithium-Sulfur Batteries. ACS Nano 2015, 9, 3002-3011. [CrossRef] [PubMed]

54. Sun, Y.; Tang, J.; Zhang, K.; Yuan, J.; Li, J.; Zhu, D.-M.; Ozawa, K.; Qin, L.-C. Comparison of reduction products from graphite oxide and graphene oxide for anode applications in lithium-ion batteries and sodium-ion batteries. Nanoscale 2017, 9, 2585-2595. [CrossRef] [PubMed]

55. Bellucci, L.; Tozzini, V. In Silico Design of Nano-Porous Graphene Scaffolds, in preparation.

56. Yang, T.; Lin, H.; Zheng, X.; Loh, K.P.; Jia, B. Tailoring pores in graphene-based materials: From generation to applications. J. Mater. Chem. A 2017, 5, 16537-16558. [CrossRef]

57. Fang, T.-H.; Lee, Z.-W.; Chang, W.-J.; Huang, C.-C. Determining porosity effect on the thermal conductivity of single-layer graphene using a molecular dynamics simulation. Phys. E Low Dimens. Syst. Nanostruct. 2019, 106, 90-94. [CrossRef]

58. Wu, C.D.; Fang, T.H.; Lo, J.Y.; Feng, Y.L. Molecular dynamics simulations of hydrogen storage capacity of few-layer graphene. J. Mol. Model. 2013, 19, 3813-3819. [CrossRef]

59. Gotzias, A.; Tylianakis, E.; Froudakis, G.; Steriotis, T.H. Theoretical study of hydrogen adsorption in oxygen functionalized carbon slit pores. Micropor. Mesopor. Mater. 2012, 154, 38-44. [CrossRef]

60. Cabria, I.; López, M.J.; Alonso, J.A. The optimum average nanopore size for hydrogen storage in carbon nanoporous materials. Carbon 2007, 45, 2649-2658. [CrossRef]

61. Georgakis, M.; Stavropoulos, G.; Sakellaropoulos, G.P. Alteration of graphene based slit pores and the effect on hydrogen molecular adsorption: A simulation study. Micropor. Mesopor. Mater. 2014, 191, 67-73. [CrossRef]

62. Kowalczyk, P.; Gauden, P.A.; Furmaniak, S.; Terzyk, A.P.; Wisniewski, M.; Ilnicka, A.; Łukaszewicz, J.; Burian, A.; Włoch, J.; Neimark, A.V. Morphologically disordered pore model for characterization of micro-mesoporous carbons. Carbon 2017, 111, 358-370. [CrossRef]

63. Patchkovskii, S.; John, S.T.; Yurchenko, S.N.; Zhechkov, L.; Heine, T.; Seifert, G. Graphene nanostructures as tunable storage media for molecular hydrogen. Proc. Natl. Acad. Sci. USA 2005, 102, 10439-10444. [CrossRef] [PubMed]

64. Kuchta, B.; Firlej, L.; Mohammadhosseini, A.; Boulet, P.; Beckner, M.; Romanos, J.; Pfeifer, P. Hypothetical high-surface-area carbons with exceptional hydrogen storage capacities: Open carbon frameworks. J. Am. Chem. Soc. 2012, 134, 15130-15137. [CrossRef] [PubMed]

65. Krainyukova, N.V.; Zubarev, E.N. Carbon honeycomb high capacity storage for gaseous and liquid species. Phys. Rev. Lett. 2016, 116, 055501. [CrossRef] [PubMed] 
66. Li, L.; Xu, M.; Song, W.; Ovcharenko, A.; Zhang, G.; Jia, D. The effect of empirical potential functions on modeling of amorphous carbon using molecular dynamics method. Appl. Surf. Sci. 2013, 286, 287-297. [CrossRef]

67. Tersoff, J. Modelling solid-state chemistry: Interatomic potentials for multicomponent systems. Phys. Rev. 1989, 39, 5566-5568. [CrossRef]

68. Stuart, S.J.; Tutein, A.B.; Harrison, J.A. A reactive potential for hydrocarbons with intermolecular interactions. J. Chem. Phys. 2000, 112, 6472-6648. [CrossRef]

69. Ghiringhelli, L.M.; Valeriani, C.; Los, J.H.; Meijer, E.J.; Fasolino, A.; Frenkel, D. State-of-the-art models for the phase diagram of carbon and diamond nucleation. Mol. Phys. 2010, 106, 2011-2038. [CrossRef]

70. Chenoweth, K.; Van Duin, A.C.; Goddard, W.A. ReaxFF reactive force field for molecular dynamics simulations of hydrocarbon oxidation. J. Phys. Chem. A 2008, 112, 1040-1053. [CrossRef]

71. Ganfoud, N.; Sene, A.; Haefele, M.; Marin-Laflèche, A.; Daffos, B.; Taberna, P.L.; Salanne, M.; Simon, P.; Rotenberg, B. Effect of the carbon microporous structure on the capacitance of aqueous supercapacitors Energy Storage Mater. Energy Storage Mater 2019, 21, 190-195. [CrossRef]

72. Mejía-Mendoza, L.M.; Valdez-Gonzalez, M.; Muniz, J.; Santiago, U.; Cuentas-Gallegos, A.K.; Robles, M. A theoretical approach to the nanoporous phase diagram of carbon. Carbon 2017, 120, 233-0243. [CrossRef]

73. Thompson, M.W.; Dyatkin, B.; Wang, H.-W.; Turner, C.H.; Sang, X.; Unocic, R.R.; Iacovella, C.R.; Gogotsi, Y.; van Duin Cummings, P.T. An Atomistic Carbide-Derived Carbon Model Generated Using ReaxFF-Based Quenched Molecular Dynamics. J. Carbon Res. C 2017, 3, 32. [CrossRef]

74. Ranganathan, R.; Rokkam, S.; Desa, T.; Keblinski, P. Generation of amorphous carbon models using liquid quench method: A reactive molecular dynamics study. Carbon 2017, 113, 87-99. [CrossRef]

75. Surendra, K.J.; Roland, J.-M.P.; Pikunic, J.P.; Gubbins, K.E. Molecular Modeling of Porous Carbons Using the Hybrid Reverse Monte Carlo Method. Langmuir 2006, 22, 9942-9948.

76. Farmahini, A.H.; Bhatia, S.K. Hybrid Reverse Monte Carlo simulationof amorphous carbon: Distinguishing betweencompeting structures obtained using differentmodeling protocols. Carbon 2015, 83, 53-70. [CrossRef]

77. Sarkisov, L. Accessible Surface Area of Porous Materials: Understanding Theoretical Limits. Adv. Mater. 2012, 24, 3130-3133. [CrossRef]

78. Baburin, I.A.; Klechikov, A.; Mercier, G.; Talyzin, A.; Seifert, G. Hydrogen adsorption by perforated graphene. Int. J. Hydrog. Energy 2015, 40, 6594-6599. [CrossRef]

79. Kostoglou, N.; Tarat, A.; Walters, I.; Ryzhkov, V.; Tampaxis, C.; Charalambopoulou, G.; Steriotis, T.; Mitterer, C.; Rebholz, C. Few-layer graphene-like flakes derived by plasma treatment: A potential material for hydrogen adsorption and storage. Microporous Mesoporous Mater. 2016, 225, 482-487. [CrossRef]

80. Klontzas, E.; Tylianakis, E.; Varshney, V.; Roy, A.K.; Froudakis, G.E. Organically interconnected graphene flakes: A flexible 3-D material with tunable electronic bandgap. Sci. Rep. 2019, 9, 13676. [CrossRef]

81. Burress, J.W.; Gadipelli, S.; Ford, J.; Simmons, J.M.; Zhou, W.; Yildirim, T. Graphene Oxide Framework Materials: Theoretical Predictions and Experimental Results. Angew. Chem. Int. Ed. 2010, 49, 8902-8904. [CrossRef]

82. Hung, W.-S.; Tsou, C.-H.; De Guzman, M.; An, Q.-F.; Liu, Y.-L.; Zhang, Y.a.-M.; Hu, C.-C.; Lee, K.-R.; Lai, J.-Y. Cross-Linking with Diamine Monomers To Prepare Composite Graphene Oxide-Framework Membranes with Varying d-Spacing. Chem. Mater. 2014, 26, 2983-2990. [CrossRef]

83. Banda, H.; Périé, S.; Daffos, B.; Taberna, P.-L.; Dubois, L.; Crosnier, O.; Simon, P.; Lee, D.; De Paëpe, G.; Duclairoir, F. Sparsely Pillared Graphene Materials for High- Performance Supercapacitors: Improving Ion Transport and Storage Capacity. ACS Nano 2019, 13, 1443-1453. [CrossRef] [PubMed]

84. Lee, K.; Yoon, Y.; Cho, Y.; Lee, S.M.; Shin, Y.; Lee, H.; Lee, H. Tunable Sub-nanopores of Graphene Flake Interlayers with Conductive Molecular Linkers for Supercapacitors. ACS Nano 2016, 10, 6799-6807. [CrossRef] [PubMed]

85. Sekar, P.; Anothumakkool, B.; Kurungot, S. 3D Polyaniline Porous Layer Anchored Pillared Graphene Sheets: Enhanced Interface Joined with High Conductivity for Better Charge Storage Applications. ACS Appl. Mater. Interfaces 2015, 7, 7661-7669. [CrossRef] [PubMed]

86. Yuan, K.; Xu, Y.; Uihlein, J.; Brunklaus, G.; Shi, L.; Heiderhoff, R.; Que, M.; Forster, M.; Chassé, T.; Pichler, T.; et al. Straightforward Generation of Pillared, Microporous Graphene Frameworks for Use in Supercapacitors. Adv. Mater. 2015, 27, 6714-6721. [CrossRef] 
87. Lee, J.H.; Kang, S.; Jaworski, J.; Kwon, K.-Y.; Seo, M.L.; Lee, J.Y.; Jung, J.H. Fluorescent Composite Hydrogels of Metal-Organic Frameworks and Functionalized Graphene Oxide. Chem. Eur. J. 2012, 18, 765-769. [CrossRef]

88. Dimitrakakis, G.K.; Tylianakis, E.; Froudakis, G.E. Pillared Graphene: A New 3-D Network Nanostructure for Enhanced Hydrogen Storage. Nano Lett. 2008, 8, 3166. [CrossRef]

89. Hassani, A.; Taghi, M.; Mosavian, H.; Ahmadpour, A.; Farhadian, N. Hybrid molecular simulation of methane storage inside pillared graphene. J. Chem. Phys. 2015, 142, 234704. [CrossRef]

90. Pedrielli, A.; Taioli, S.; Garberoglio, G.; Pugno, N.M. Gas adsorption and dynamics in Pillared Graphene Frameworks. Microporous Mesoporous Mater. 2018, 257, 222-231. [CrossRef]

91. Garberoglio, G.; Pugno, N.M.; Taioli, S. Gas adsorption and separation in realistic and idealized frameworks of organic pillared graphene: A comparative study. J. Phys. Chem. C 2015, 119, 1980-1987. [CrossRef]

92. Mahdizadeh, S.J.; Goharshadi, E.K.; Akhlamadia, G. Seawater desalination using pillared graphene as a novel nano-membrane in reverse osmosis process: Nonequilibrium MD simulation study. Phys. Chem. Chem. Phys. 2018, 20, 22241. [CrossRef]

93. Wang, Y.C.; Zhu, Y.; FCWang Liu, X.Y.; Wu, H.A. Super-elasticity and deformation mechanism of three-dimensional pillared graphene network structures. Carbon 2017, 118, 588-596. [CrossRef]

94. Ciammaruchi, L.; Bellucci, L.; Comeron Castillo, G.; Martínez-DenegriSanchez, G.; Liu, Q.; Tozzini Martorell, J. Water splitting for hydrogen chemisorption in graphene oxide dynamically evolving to a graphane character lattice. Carbon 2019, 153, 234-241. [CrossRef]

95. Morimoto, N.; Kubo, T.; Nishina, Y. Tailoring the Oxygen Content of Graphite and Reduced Graphene Oxide for Specific Applications. Sci. Rep. 2016, 6, 21715. [CrossRef] [PubMed]

96. Zhang, Y.; Zhang, L.; Zhou, C. Review of Chemical Vapor Deposition of Graphene and Related Applications. Acc. Chem. Res. 2013, 46, 2329-2339. [CrossRef]

97. Riedl, C.; Coletti, C.; Starke, U. Structural and Electronic Properties of Epitaxial Graphene on SiC(0001): A Review of Growth, Characterization, Transfer Doping and Hydrogen Intercalation. J. Phys. D Appl. Phys. 2010, 43, 374009. [CrossRef]

98. Mashoff, T.; Convertino, D.; Miseikis, V.; Coletti, C.; Piazza, V.; Tozzini, V.; Beltram, F.; Heun, S. Increasing the active surface of titanium islands on graphene by nitrogen sputtering. Appl. Phys. Lett. 2015, 106, 083901. [CrossRef]

99. Takahashi, K.; Isobe, S.; Omori, K.; Mashoff, T.; Convertino, D.; Miseikis, V.; Coletti, C.; Tozzini, V.; Heun, S. Revealing the Multi-Bonding State Between Hydrogen and Graphene-Supported Ti Clusters. J. Phys. Chem. C 2016, 120, 12974. [CrossRef]

100. Wang, Q.H.; Jin, Z.; Kim, K.K.; Hilmer, A.J.; Paulus, G.L.C.; Shih, C.-J.; Ham, M.-H.; Sanchez-Yamagishi, J.D.; Watanabe, K.; Taniguchi, T.; et al. Understanding and controlling the substrate effect on graphene electron-transfer chemistry via reactivity imprint lithography. Nat. Chem. 2012, 4, 724. [CrossRef]

101. Navarro, J.J.; Leret, S.; Calleja, F.; Stradi, D.; Black, A.; Bernardo-Gavito, R.; Garnica, M. Organic Covalent Patterning of Nanostructured Graphene with Selectivity at the Atomic Level. Nano Lett. 2016, 16, 355-361. [CrossRef]

102. Romero-Muñiz, C.; Martín-Recio, A.; Pou, P.; Gómez-Rodríguez, J.M.; Pérez, R. Substrate-induced enhancement of the chemical reactivity in metal-supported graphene. Phys. Chem. Chem. Phys. 2018, 20, 19492-19499. [CrossRef]

103. Criado, A.; Melchionna, M.; Marchesan, S.; Prato, M. The Covalent Functionalization of Graphene on Substrates. Angew. Chem. 2015, 54, 10734. [CrossRef] [PubMed]

104. Wu, Q.; Wu, Y.; Hao, Y.; Geng, J.; Charlton, M.; Chen, S.; Ren, Y.; Ji, H.; Li, H.; Boukhvalov, D.W.; et al. Selective surface functionalization at regions of high local curvature in graphene. Chem. Commun. 2013, 49, 677-679. [CrossRef] [PubMed]

105. Bissett, M.A.; Konabe, S.; Okada, S.; Tsuji, M.; Ago, H. Enhanced chemical reactivity of graphene induced by mechanical strain. ACS Nano 2013, 7, 10335-10343. [CrossRef] [PubMed]

106. Bellucci, L.; Cavallucci, T.; Tozzini, V. From the Buffer Layer to Graphene on Silicon Carbide: Exploring Morphologies by Computer Modeling. Front. Mater. 2019, 6, 198. [CrossRef]

107. Goler, S.; Coletti, C.; Piazza, V.; Pingue, P.; Colangelo, F.; Pellegrini, V.; Emtsev, K.V.; Forti, S.; Starke, U.; Heun, S.; et al. Revealing the Atomic Structure of the Buffer Layer between SiC (0001) and Epitaxial Graphene. Carbon 2013, 51, 249. [CrossRef] 
108. Cavallucci, T.; Tozzini, V. Multistable Rippling of Graphene on SiC: A Density Functional Theory Study. J. Phys. Chem C 2016, 120, 7670. [CrossRef]

109. Fiori, S.; Murata, Y.; Veronesi, S.; Rossi, A.; Coletti, C.; Heun, S. Li-intercalated graphene on SiC (0001): An STM study. Phys. Rev. B 2017, 96, 125429. [CrossRef]

110. Riedl, C.; Coletti, C.; Iwasaki, T.; Zakharov, A.A.; Starke, U. Quasi-Free-Standing Epitaxial Graphene on SiC Obtained by Hydrogen Intercalation. Phys. Rev. Lett. 2009, 103, 246804. [CrossRef]

111. Murata, Y.; Mashoff, T.; Takamura, M.; Tanabe, S.; Hibino, H.; Beltram, F.; Heun, S. Correlation between morphology and transport properties of quasi free standing monolayer graphene. Appl. Phys. Lett. 2014, 105, 221604. [CrossRef]

112. Murata, Y.; Cavallucci, T.; Tozzini, V.; Pavliček, N.; Gross, L.; Meyer, G.; Takamura, M.; Hibino, H.; Beltram, F.; Heun, S. Atomic and electronic structure of Si dangling bonds in quasi-free-standing monolayer graphene. Nano Res. 2018, 11, 864. [CrossRef]

113. Cavallucci, T.; Murata, Y.; Heun, S.; Tozzini, V. Unraveling localized states in quasi free standing monolayer graphene by means of Density Functional Theory. Carbon 2018, 130, 466-474. [CrossRef]

114. Hess, L.H.; Lyuleeva, A.; Blaschke, B.M.; Sachsenhauser, M.; Seifert, M.; Garrido, J.A.; Coulombwall, A. Graphene Transistors with Multifunctional Polymer Brushes for Biosensing Applications. ACS Appl. Mater. Interfaces 2014, 6, 9705. [CrossRef] [PubMed]

(C) 2020 by the authors. Licensee MDPI, Basel, Switzerland. This article is an open access article distributed under the terms and conditions of the Creative Commons Attribution (CC BY) license (http://creativecommons.org/licenses/by/4.0/). 